\title{
Aproximaciones para estudiar la relación entre música, cultura y sociedad en la historia.
}

\author{
Fernando de Jesús Serrano Arias \\ fernando.serrano@unison.mx \\ Departamento de Bellas Artes \\ Carlos Adrián Montaño Gaytán \\ carlos_adrian69@hotmail.com \\ Departamento de Letras y Lingüística \\ Universidad de Sonora
}

\section{Introducción}

En este artículo exponemos una forma de acercarnos al estudio de la relación entre música, cultura y sociedad, durante la década de 1920 en la ciudad de Hermosillo, Sonora, México. Nos referimos a un tipo de estudio que pone en relación el estudio hemerográfico con el bibliográfico, cuyos resultados conjuntos aportan una construcción organizadora del fenómeno bajo estudio.

El estudio hemerográfico nos permite identificar, seleccionar y registrar notas periodísticas de la publicación El Observador, semanario de anuncios y variedades, aparecidas durante el período de 1920-1923. Se trata de comprender los rasgos de la cultura y la sociedad de la época, apoyándonos en las afirmaciones tomadas de dicha revisión. Mientras que, la revisión bibliográfica nos permite recuperar estudios sobre la relación de la música con la cultura. Retómanos aquí, el trabajo de Pierre Bourdieu, en particular lo expuesto en El sentido social del gusto (2010); el trabajo de Elie Siegmeister, Música y sociedad (1980), una obra publicada en 1938, en la que se expone la necesidad de vincular el estudio de la música con la sociedad en la que se crea, ideas aún vigentes para el estudio de la historia de la música. Así como las opiniones de Zarate Toscano (2014), sobre la identidad nacional en las partituras pu- blicadas, ya que se apoya en documentos impresos y propone una forma de analizar este tipo de fuentes sobre música en su artículo: La sinfonía de la identidad mexicana en la música a fines del siglo XIX. Ambos estudios son puestos en relación, donde el trabajo hemerográfico sirve de fuente primaria (hecho o fenómeno) para ser orientado a través del trabajo bibliográfico, en el cual, el fenómeno es estudiado desde la lógica histórica, cuyo interés es la cultura escrita e impresa y no la crítica musical, como sugiere Suárez de la Torre (2014).

La pertinencia de esta clase de estudios se pone de manifiesto si recuperamos las palabras de Rocío Terán, expresados en La familia Escobar. Un legado de música sonorense donde afirma: "las investigaciones que han abordado temas de cultura artística [en Sonora] son escasas y, por consiguiente, no se puede difundir o dar a conocer la cultura de un estado si aún el propio estado no la identifica en su totalidad" (2010, p. 7).

En este sentido, las exiguas investigaciones sobre música sonorense se centran en el compositor y la existencia de orquesta locales, esta investigación está centrada en la sociedad que las producía y consumía, un aspecto poco abordado y que, esperamos contribuya en la ampliación de nuestra comprensión de la cultura musical sonorense. 
En el siguiente apartado se realiza un breve repaso sobre parte de la obra y las ideas de los autores mencionados que pueden ser usadas para hacer una lectura de la fuente hemerográfica.

\section{Ideas a considerar para el análisis de la relación entre arte, música y sociedad}

Se consideran tres autores para realizar un ejercicio de síntesis en el análisis de la cultura y los gustos musicales de los hermosillenses de 1920; estos tres autores pertenecen a disciplinas diferentes y sus investigaciones manejan metodologías distintas, lo que nos ofrece una visión variada de la lectura de la fuente hemerográfica.

El primer autor, Pierre Bourdieu, fue un sociólogo francés de la segunda mitad del siglo XX. Realizó varias investigaciones sociales y generó una teoría sobre la cultura en las que considera el arte y la estrecha relación que tiene con la sociedad. Este autor sostiene que los gustos y disgustos musicales no son, en el mundo moderno, cuestiones meramente espirituales o subjetivas, y el consumo de productos relacionados con la música al respecto afirma:

la observación científica muestra que las necesidades culturales son productos de la educación: la investigación establece que todas las prácticas cul-

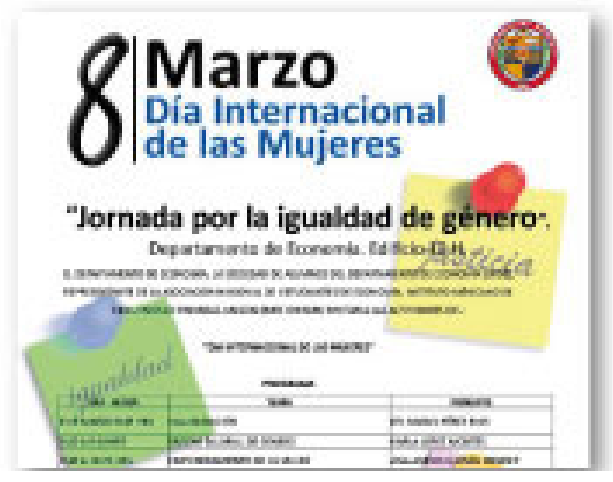

turales y las preferencias correspondientes están estrechamente ligadas al nivel de instrucción y, en segundo lugar, al origen social. (Bourdieu; 2010, p. 231)

Bourdieu le da una importancia central a la educación de las personas para desarrollar un determinado gusto por algunas expresiones del arte y de la música, no solo se refiere a una educación formal y escolarizada, sino también, a la educación en la familia y el grupo de amigos o clases social con la que se convive. Con esto entonces tenemos que tomar en cuenta estos dos aspectos: origen social y educación. En la obra titulada "El sentido social del gusto" Bourdieu hace una categorización sobre la producción del arte de tres formas: arte bajo, arte medio y arte erudito; sobre el arte medio, que es el que nos interesa en este artículo, afirma:

La misma heteronomía caracteriza la recepción del arte medio, siempre obsesionado por la referencia al arte erudito. Si la cultura media no puede reivindicar su autonomía se debe, entre otras razones, a que debe una parte de su encanto, para quienes lo consumen, a las referencias a la cultura erudita que encierra y que inclinan y autorizan a identificarla con esa cultura. Esto se observa en ese género típico de la cultura media que es "la adaptación": obras cinematográficas inspiradas en

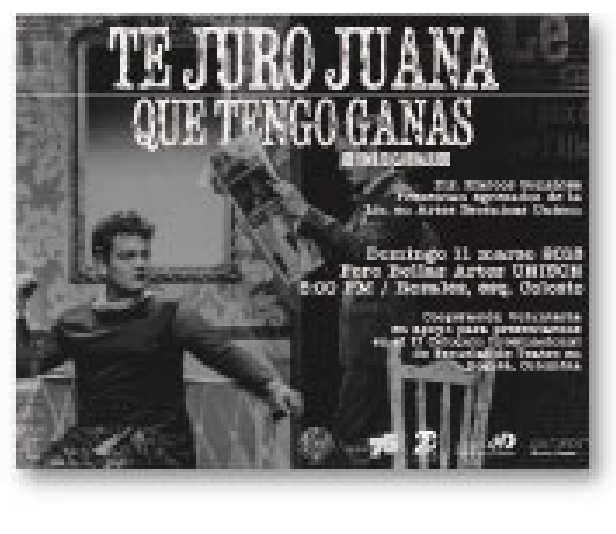




\section{(Arte)}

obras de teatro o novelas, "orquestaciones populares" de música erudita o, inversamente, "orquestaciones" con apariencia erudita de aires "populares", para no mencionar las "interpretaciones" vocales de obras clásicas en un estilo que evoca, a la vez, la canción scout y el coro de ángeles. (Bourdieu; 2010, p.121)

Con la afirmación anterior se pude entonces considerar el nivel educativo que tenían algunos de los consumidores y lectores a quienes estaba dirigido el semanario, además de que se puede considerar la clase social a las que pertenecen, pero también a una coacción o sujeción al arte erudito.

Por otro lado, Siegmeister, es un autor y compositor estadounidense, que realiza una breve monografía titulada Música y sociedad. En esta obra, afirma la estrecha relación de la música y la sociedad. Siegmeister utiliza la frase "las funciones sociales" de la música, dependiendo de la cultura y la época.

Una vez que empezamos a considerar a este arte [música] como parte del organismo social, influido prácticamente por todo lo demás que hay en la sociedad e influyendo en ella, despertamos en forma brusca del idílico mundo de ensueño..., encontramos que, de los pies a la cabeza, está sufriendo las angustias de la crisis tan severa que afec- ta a cualquier otro aspecto, económico y cultural de la sociedad de nuestros días (Siegmeister; 1980, pp. 9-10).

En esta cita expresa la importancia que la música tiene en la sociedad y lo mucho que la sociedad puede influir en su producción y difusión. Por otro lado, la música, suele ser apropiada por grupos hegemónicos que dan un lugar a ciertos estilos y compositores de una única expresión culturalmente aceptada. Seigmeister también afirma:

Si realmente tenemos que valorar el lugar y las potencialidades de la música como una parte de la civilización, es necesario examinarla objetivamente conforme fue apareciendo en diferentes momentos de la historia, considerar su relación con la vida y la sociedad, y como esa relación fue evolucionando desde los primeros tiempos hasta nuestros días (Siegmeister; 1980, p. 27).

El autor que comentamos, continua mencionando funciones sociales de la música para la era moderna, afirma que: "La música empieza a usarse como señal de prestigio social" (Siegmeister; 1980, p. 34). Esto es posible de identificar en las notas de El Observador en cuanto que reseñan reuniones culturales en las que participan miembros de la sociedad hermosillense. Suárez de la Torre (2014), hace una afir-

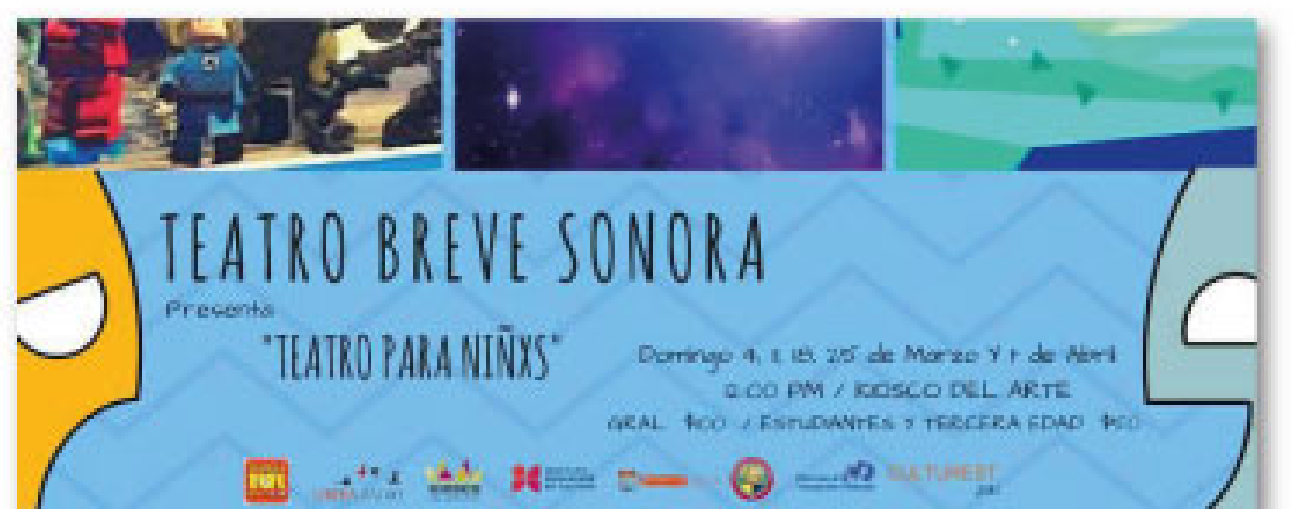


mación que puede servir de guía para abordar la información de los documentos impresos y hemerográficos: "Nos referimos al mundo de la música y no a ésta, lo abordamos como historiadores interesados en la cultura escrita e impresa y no como críticos musicales" (P. 9). Suárez de la Torre deja en claro que las posibilidades y las limitantes de estudiar la historia de la música desde este tipo de documentos. En lo que respecta a la aportación de Zarate (2014) hace una descripción de los posibles consumidores de partituras, documentos que ella analiza:

[...] ahondando aún más en los consumidores, podríamos señalar dos tipos: por un lado aquellos que podríamos denominar "músicos cautivos" que esperaban con avidez la aparición de nuevas composiciones para ejecutarlas, sin importar las características de las portadas. Y por otro, aquellos que adquirían los impresos simplemente por su valor estético o por que las habían recibido como un obsequio. Pero tampoco hay que pasar por alto que las partituras eran una mercancía y que la edición y comercio de música estaban sujetos a la ley de la oferta y la demanda, a la vez que eran un medio de vida para los empresarios que se dedicaran a estas actividades. (p. 237).

Habla de dos posibles consumidores de partituras y lo que los pude inclinar a ob-

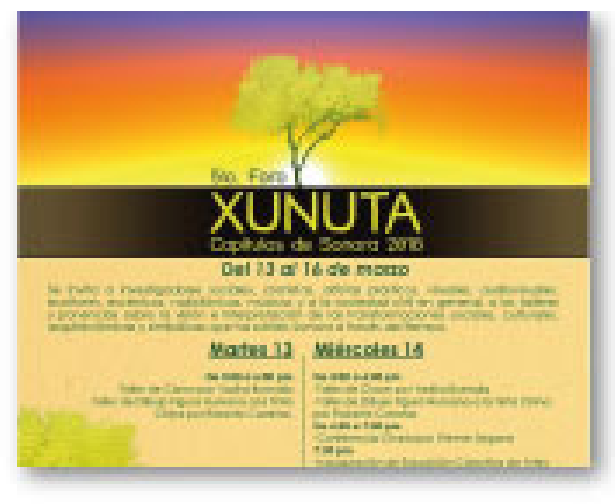

tenerlas. Se puede relacionar tanto con los consumidores de instrumentos, clases de música y quienes contrataban orquestas en Hermosillo.

Los espectáculos que se ofrecen en Hermosillo (o se anuncian), nos hablan de un publico con cierta educación, también las noticias sobre músicos y compositores extranjeros. Las noticias sobre músicos y compositores nacionales son una pauta sobre la educación y la clase social, pero también son puntos de identidad nacional como señala Zarate (2014), que además construye la historia de la música a través del documento impreso y analizando los elementos gráficos.

Si tiene una educación pertenece a alguna clase social (lo que Seigmeister define como función social), además, tiene acceso a algún instrumento para tener formación musical. Así, en El Observador se ofertan instrumentos y por otro lado se anuncian orquestas para amenizar reuniones sociales donde se presentan los aspectos a considerar, que son: la educación, la función social de la música y la identidad nacional.

La diferencia temporal y espacial, además de disciplinaria de los autores mencionados, nos permite un tener un panorama más amplio y también menos rígido al analizar las notas periodísticas que se exponen en el apartado siguiente.

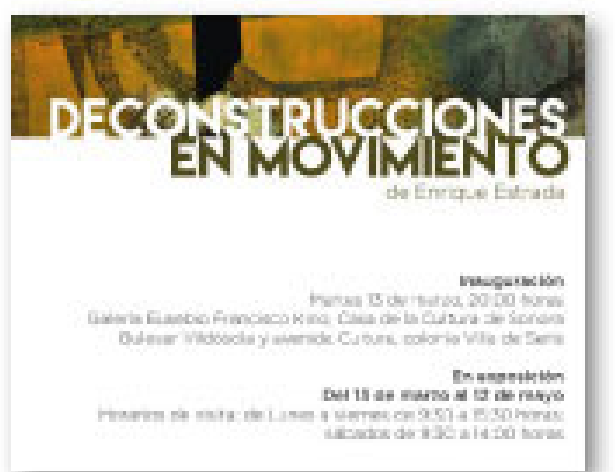




\section{(Arte)}

\section{Oferta de cultura musical en El Observador}

En este apartado se muestran las noticias y anuncios sobre música, considerando los aspectos mencionados líneas arriba: la educación, la función social de la música y la identidad nacional. Lo que se encuentra en los artículos y anuncios de El Observador son aspectos sociales, culturales, de oferta cultural y de identidad nacional, todos relacionados con la música y las funciones que ésta tiene en Hermosillo, en un grupo social de una cultura local en un tiempo determinado.

En algunas notas del semanario debemos advertir el nivel de educación musical que se espera de sus lectores al dar noticias de músicos de talla internacional; por ejemplo: "El Gran Tenor Caruso Murió en Nápoles", publicada el 13 de agosto de 1921. En la edición del seis de diciembre de 1924 publicaron el siguiente encabezado: "Giácomo Puccini, el tan famoso compositor murió en Bruselas". Es claro que el público al que van dirigidas estas notas tiene algo de educación musical.

Otra noticia que se publica, y que da cuenta también de los músicos nacionales, aparece el diez de febrero de 1923 y se refiere al compositor Felipe Villanueva. El encabezado dice: "Los restos de Villanueva serán llevados a la capital"; en ella se informa que el "Departamento de Bellas Artes de la Secretaria de Edu-

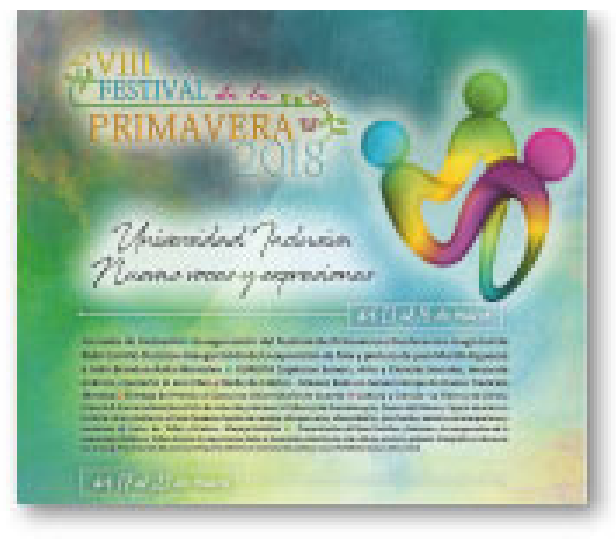

cación Pública" trasladará de Puebla a la ciudad de México los restos del compositor y se le erigirá una capilla ardiente en el salón de actos del Museo Nacional. Reiterando lo que se refiere a tener una educación o por lo menos estar informado de quién era este personaje; por otro lado, se están generando símbolos de nacionalismo, al darle un lugar especial para sus restos a este compositor. En mayo 19 de 1923 se publica otra noticia relacionado con un poeta y compositor mexicano, con el encabezado: "Lamentable perdida"; se informa de la muerte de Jesús Villalpando, continuando con la creación de una identidad nacional a través de los compositores y su música.

Esta búsqueda de identidad nacional y de la función social de la música se pueden observar al leer en las páginas de $E l$ Observador; por ejemplo, se publica una nota en la que se hace explicita la mala opinión que se tenía sobre el Jazz: "Activas labores del Consejo cultural. Se procurará desterrar del país al "Jazz Band" (27 de mayo de 1922). En esta nota se informa que se han presentado iniciativas de algunos socios de dicho consejo. Una se refiere a el reglamento de teatros; la otra es que se forme una comisión que se encargue de desterrar el jazz; refiriéndose a este como "música zoológica", además de que no se le permita la difusión de otras expresiones musicales de Estado

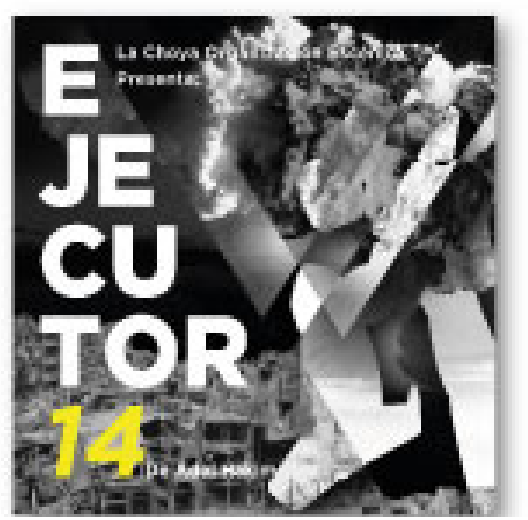


Unidos. Se solicita que se le dé difusión al folclore musical y se cultive la música nacional.

Por otro lado, se refieren al jazz como música sin arte, al final de la nota se hace la siguiente afirmación:

Ojalá, decimos nosotros, que la acción del Consejo Cultural de la ciudad de México llegue hasta nosotros, los que vivimos cerco de por medio con los Estados Unidos, que ya no oímos por la calle, cines, teatros y hasta en los salones de las aristocráticas casas de nuestros ricos, otra música que la de los negros "del otro lado", de la cual se saben piezas enteras y silban con deleite los chicos mexicanos. ( $\mathrm{El} \mathrm{Ob}$ servador, 1922)

Recuperando la afirmación de Bourdieu (2010), sobre que el gusto está estrechamente ligado a la educación, lo podemos observar cuando menciona que esta música se escucha hasta "en los salones de las aristocráticas casas", dando a entender que se espera que por lo menos esta clase social demuestre su educación y por la tanto su gusto por expresiones musicales acordes con su condición social.

A primera vista se puede notar un racismo de parte del Consejo Cultural, hacia esta expresión musical. Si se revisa con más detenimiento en esta cita se evidencia que se siente amenazada la identidad nacional, identidad que debería de ser

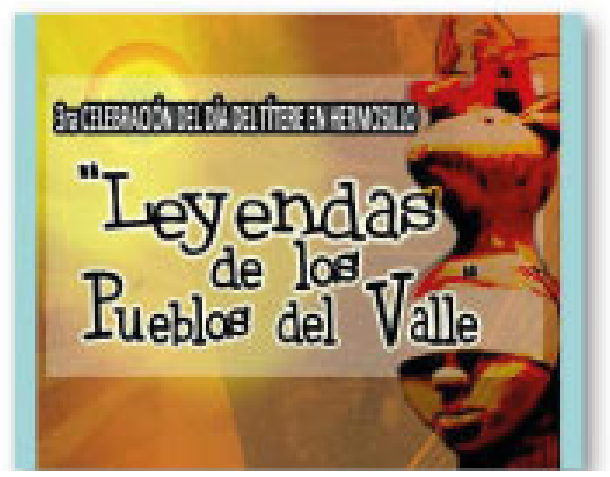

reforzada y/o difundida por la música. Como lo señala Zarate (2014) en su artículo; si bien ella lo ve en las portadas de partituras publicadas, en los comentarios de esta nota también se encuentran rasgos de la defensa de la identidad nacional, así como de la función social que se espera de la música, es decir, crear identidad nacional.

A este respecto, una nota encabezada "Bando solemne", notifica:

El miércoles, por la tarde las tropas de la guarnición recorrian las calles de Hermosillo con la banda de música a la cabeza y seguida de carruajes, automoviles y pueblo... Era que habiéndose recibido el Decreto del Congreso de la Union, por el cual se declara Presidente de la Republica para el próximo periodo al ilustre sonorense Gral. De Division Alvaro Obregon" (El Observador; 1920).

En esta noticia se ve cómo la musica es utilizada para legitimar el ascenso de una persona en el poder politico.

Zárate(2014) hace una descripción de los probables consumidores de las partituras que ella usa como fuente, los anuncios en "El Observador" dan evidencia de la existencia de un tipo de consumidor de artículos musicales.

Con respecto al consumo musical en Hermosillo existen varias notas referentes a espectáculos musicales en Hermosillo y

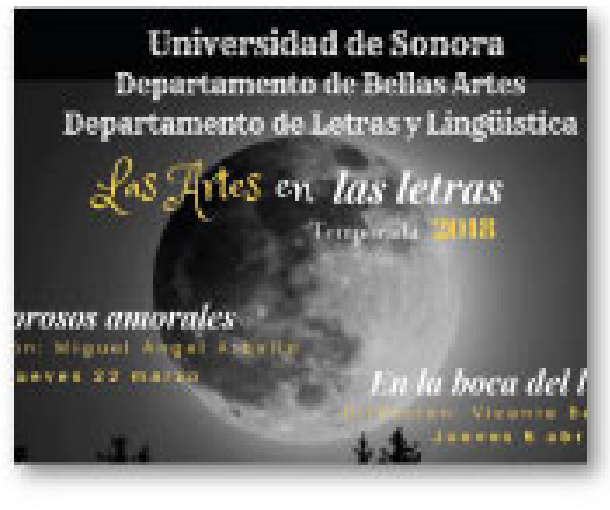




\section{(Arte)}

venta de artículos musicales, en estas notas se aprecia la existencia de una oferta comercial. Se puede asegurar que los que consumían este tipo de productos eran músicos ejecutantes de algunas de las orquestas locales, por un lado, por el otro, eran familias acomodadas que disfrutaban de educar a sus hija(o)s principalmente en la ejecución de algún instrumento, como practica de distinción social, donde, el instrumento favorito, es el piano. Entre los servicios que se ofertan está la afinación y reparación de pianos, además de la venta de estos instrumentos y por supuesto clases de música para señoritas.

Un producto musical que seguramente fue consumido por familias acomodadas era la victrola, pieza que fue ofertada en la publicación por Jesús del Raso, quien además vendía discos de los mejores cantantes del "universo". Este objeto también fue símbolo de distinción social.

Por otro lado, entre lo que se ofertaba, se anuncian clases de música y el servicio de orquestas, en este caso se anuncia "La Orquesta Amezcua", junto con el anuncio de un curso de de solfeo dirigido a niños, por parte del Prof. Angel Arriola.

Otro de los sucesos cubierto por " $\mathrm{El} \mathrm{Ob}$ servador" es el Congreso de Escritores y Artistas Mexicanos. Se publicaron cuatro notas; la primera el 17 de marzo de 1923, en la cual se menciona que se hacen los preparativos para inciar dicho congreso y se abre una convocatoria nacional. El 28

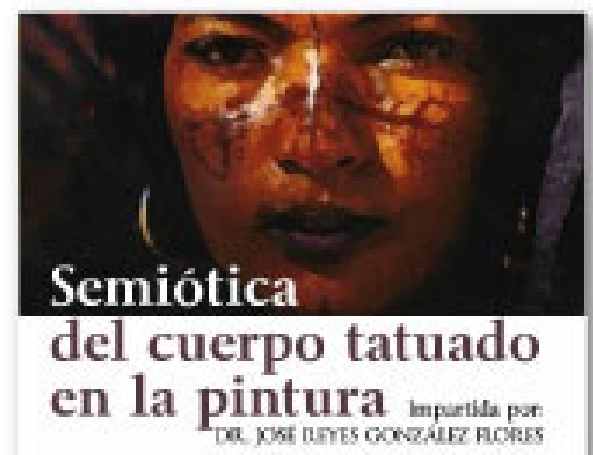

de abril del mismo año se publican dos notas referentes a este congreso y la ultima el 19 de mayo en la que se anuncia que dio fin este congreso. Con respecto a la música se convoca a los compositres sonorenses que envien sus composiciones las cuales serán enviadas para un concurso que se realiza en el marco de dicho congreso.

En Sonora, se forma un comité para elegir las obras que serán enviadas al concurso musical. Además que se tiene la iniciativa de realizar un concierto como se menciona en la nota publicada el 28 de abril de 1923: "Se está organizando, para el martes próximo, en el Teatro Noriega un concierto artístico, con valiosísimos elementos de esta capital, y cuyos productos se destinarán para los fines de propaganda correspondientes." Si bien es un congreso de escritores y artistas, la música tiene un papel destacado, de hecho no mencionan nada sobre otras expresiones artísticas. Con respecto a los espectaculos musicales en Hermosillo es posible, a partir de las notas de El Observador, identificar dos lugares en donde se llevaban a cabo este tipo de eventos, uno es el salón "Atenas"; que en una nota del 25 de febrero de 1922 nos informa:

El lunes hizo su debut en el aristocratico Salón Atenas la bella y gentil tonadillera española María Valdealde Fuentes, mereciendo del respetable

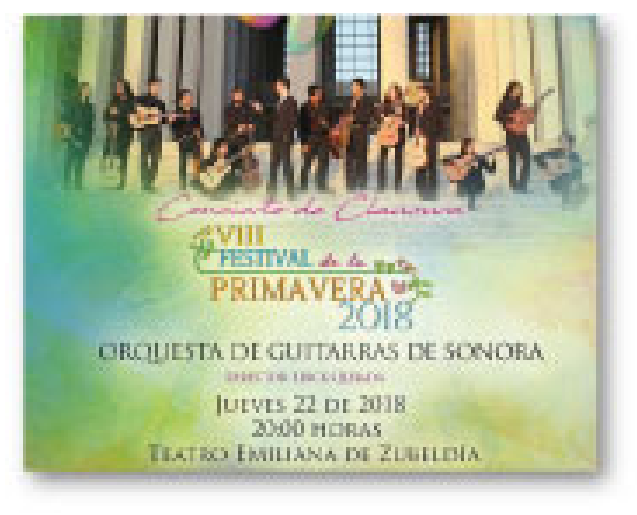


nutridos y repetidos aplausos, que nosotros, desde las columnas de nuestro "Observador" se los tributamos entusiastas y sinceros (El Observador ,1922).

Se usa la palabra "aristocrático" haciendo referencia a lo importante del lugar y el tipo de personas que se espera que esten presentes en dicho espectaculo. Otro de los sitios donde solía haber conciertos es el teatro "Noriega", que es mencionado en una nota del siete de abril de 1923:

Con regular éxito pecunario está dando Conciertos en el Noriega la conocida cantante Fany Anitúa, quien arribó a esta capital después de trabajar en algunos puntos del sur, entre otros, Navojoa y Guaymas. Fany Anitúa fue muy aplaudida y en breve sale en gira artística por algunos lugares de Arizona (El Observador, 1923).

Estos son ejemplos de algunos de los espectáculos a los que acudían los hermosillenses, cierta parte de la sociedad. En otras paginas del semanario se anuncian y mencionan otros espectaculos o el arribo de orquestas que venían de la Ciudad de México; tambien se daban noticias de orquestas mexicanas que tenian éxito en Estados Unidos.

\section{Conclusiones}

Retomando los aspectos de educacion, identidad nacional y funcion social, se pude observar que la sociedad sonorense, de la decada de 1920, tenían formación musical y eran conocedores de compositores de talla internacional. Por otro lado consumían instrumentos, clases de música y asistían a espectáculos musicales. La funcion social que refleja las paginas de "El Observador" es el uso de la música como aspecto de distincion social, es decir que las familias acomodadas apreciaban que sus hijos obtuvieran conocimientos y destreza musical, algo que era espcialmente bien visto en las señoritas de sociedad.

Con respecto a los espectáculos también queda patente la educación y los gustos de los hermosillenses, ademas de la oferta cultural existente en la ciudad. Los artistas mencionados prometen excelentes interpretaciones además de un repertorio a la altura del publico.

Las notas sobre la muerte o los eventos en honor de estos recuerda la difusión y formación de una identidad nacional, por otro lado el ataque a estilos musicales extranjeros se justifica en la defensa de esta identidad nacional. La nota en la que se ataca la música de jazz además nos permite observar la relación con las clases sociales cuando critica que hasta los jovenes aristocraticos gustan de esta música, hace referencia a una falta de educacion.

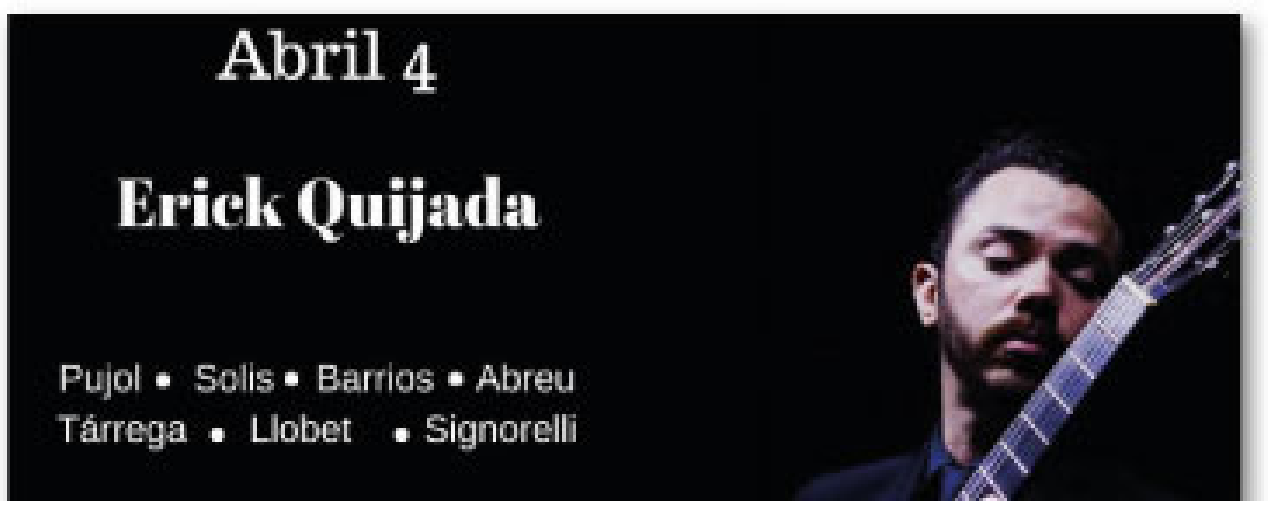




\section{Bibliografía}

Bourdieu, P. (2010). El sentido social del gusto. Elementos para una sociología de la cultura. En P. Bourdieu, El sentido social del gusto. Elementos para una sociología de la cultura (primera ed., pág. 282). Argentina: Siglo Veintiuno.

Montaño Gaytán, C. (2016). Oferta de cultura, arte y música en los medios impresos de Hermosillo, Sonora. El caso 'El Observador, semanario de variedades y anuncios’. 1920-1924. México: Universidad de Sonora. Tesis de Maestría. Director Fernando de Jesús Serrano Arias

Siegmeister, E. (1980). Música y sociedad. México, España, Argentina, Colombia: Siglo Veintiuno Editores.

Suárez de la Torre, L. (2014). Estudio Introductorio. En L. Suárez de la Torre, Los Papeles para Euterpe. La música en la Ciudad de México desde la historia cultural. Siglo XIX (pág. 9). México: Instituto de Investigaciones Dr. José María Luis Mora. Consejo Nacional de Ciencia y Tecnología.

Terán Díaz Landa, R. (2010). La familia Escobar. Un legado de música sonorense. Hermosillo; Sonora, México: Instituto Sonorense de Cultura.

Zárate Toscano , V. (2014). La sinfonía de la identidad mexicana en la múisca a fines del siglo XIX. En L. Suárez de la Torre, Los papeles para Euterpe. La música en la Ciudad de México desde la historia cultural. Siglo XIX (págs. 230-289). México: Instituto de Investigaciones Dr. José María Luis Mora.

\section{Hemerografía}

El Observador, semanario de anuncios y variedades. 1920-1923. Hermosillo, Sonora, México.
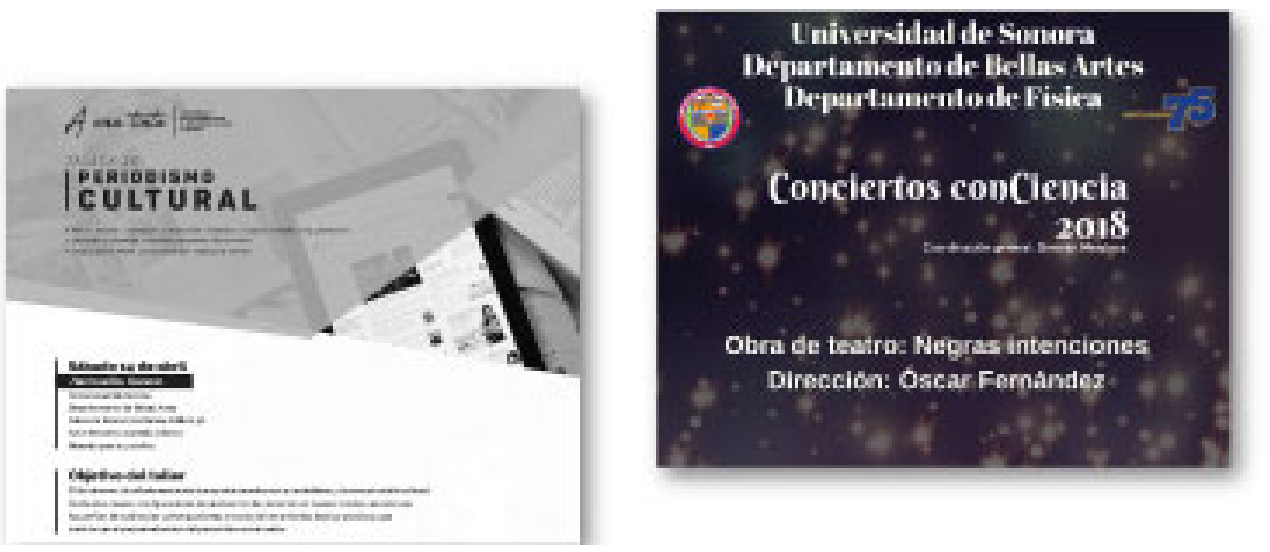